\title{
Packaging and Temperature Compensation of Fiber Bragg Grating for Strain Sensing: A Survey
}

\author{
Yi KUANG ${ }^{1,2}$, Yongxing GUO ${ }^{1,2^{*}}$, Li XIONG ${ }^{1,2}$, and Wenlong LIU ${ }^{1,2}$ \\ ${ }^{1}$ Key Laboratory of Metallurgical Equipment and Control Technology, Ministry of Education, Wuhan University of \\ Science and Technology, Wuhan 430081, China \\ ${ }^{2}$ Hubei Key Laboratory of Mechanical Transmission and Manufacturing Engineering, Wuhan University of Science and \\ Technology, Wuhan 430081, China \\ *Corresponding author: Yongxing GUO \\ E-mail: yongxing_guo@wust.edu.cn
}

\begin{abstract}
During last decades, sensor elements based on the fiber Bragg grating (FBG) have been widely studied and developed due to the advantages of immunity to electromagnetic interference, compact size, high precision, and so on. The FBG itself is sensitive to axial strain and temperature variation directly and can indirectly measure these complex physical parameters, such as pressure, displacement, and vibration, by using some specially designed elastic structures to convert them into the axial strain of the FBG. Whether the FBG is fixed on the measured object to measure the strain directly or fixed on an elastic structure body to measure other physical quantities, these types of FBGs could be collectively called as strain sensing FBGs. The packaging of the FBG has important influence on FBG characteristics that directly affect the measurement accuracy, such as strain transfer, temperature characteristic, and spectral shape. This paper summarizes the packaging methods and corresponding temperature compensation methods of the currently reported strain sensing FBGs, focusing especially on fully pasted FBG, pre-stretched FBG with double-end fixed, and metallic packaging. Furthermore, the advantages and drawbacks of different packaging methods have been analyzed, which can provide a reference for future researches.
\end{abstract}

Keywords: Fiber Bragg grating (FBG); strain sensing FBG; packaging; temperature compensation

Citation: Yi KUANG, Yongxing GUO, Li XIONG, and Wenlong LIU, "Packaging and Temperature Compensation of Fiber Bragg Grating for Strain Sensing: A Survey," Photonic Sensors, 2018, 8(4): 320-331.

\section{Introduction}

In 1978, the presence of fiber grating was first demonstrated by Hill et al. at the Ottawa Communication Research Center in Canada [1, 2]. In 1989, the fiber grating was first used for sensing detection by Morey et al. at the United Technologies Research Center of the United States [3]. The sensing principle of the grating to the strain and temperature variations has been described, which promoted the development of the fiber grating as a sensing element. Since then, the optical fiber grating sensing technology had ushered in its booming period. The sensing technology based on the fiber grating has been widely used in civil engineering, machinery and equipment, robotic, medicine, and aero space, among others [4-6]. The varieties of optical fiber gratings commonly used include fiber Bragg grating (FBG), blazed fiber Bragg grating (BFBG), chirped fiber Bragg grating (CFBG), and

Received: 4 December 2017 / Revised: 30 May 2018

(C) The Author(s) 2018. This article is published with open access at Springerlink.com

DOI: 10.1007/s13320-018-0504-y

Article type: Review 
long-period fiber grating(LPFG), among them, FBG, which is the earliest researched grating, is also the most widely used in the optical fiber sensing field.

Figure 1 shows the sensing principle of the FBG. The Bragg grating is engraved into a single-mode fiber core by using laser. Light from broad band source (BBS) illuminating the fiber is used as the light input to the fiber grating, and the FBG reflects the spectral signal of a specific wavelength. When the axial strain and temperature vary, the FBG reflective central wavelength will regularly shift. The relationship between the wavelength shift of the FBG and temperature and axial strain is given as follows [7]:

$$
\frac{\Delta \lambda}{\lambda}=\left(\alpha_{f}+\xi\right) \Delta T+\left(1-P_{e}\right) \Delta \varepsilon
$$

where $\lambda$ is the initial central wavelength of the FBG, $\Delta \lambda$ is the wavelength drift of the grating, $\alpha_{f}$ is the thermal expansion coefficient of the optical fiber, $\xi$ is the thermal-optic coefficient, and $P_{e}$ is the strain-optic coefficient.

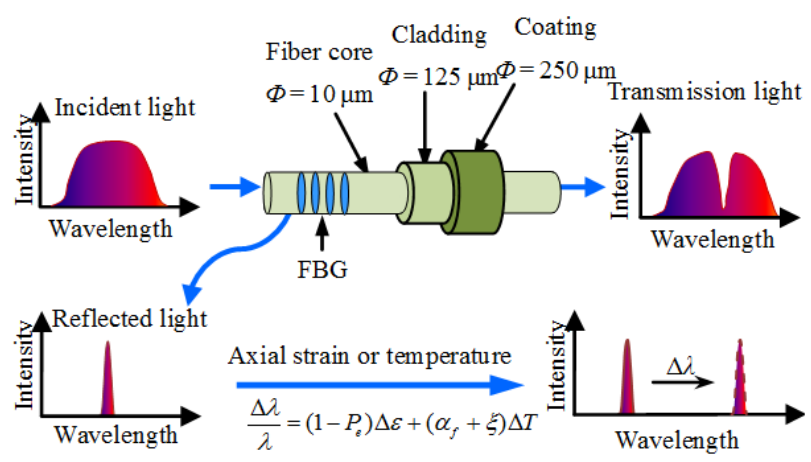

Fig. 1 Schematic diagram of the sensing principle of fiber Bragg grating.

Obviously, the physical parameters measured directly by the FBG sensor are axial strain and temperature. To measure the other physical parameters (e.g., pressure, displacement, and vibration), an elastic structure is needed to convert the measured physical parameters into the axial strain exerted on the FBG. As shown in Fig. 2, when these physical parameters are exerted on the elastic structure body, the body will produce deformation. FBG is arranged at the deformation part of the elastic body and sensing deformation strain, which causes the shift of wavelength. After calibration experiment, these physical quantities can be obtained by detecting the wavelength shifts. Whether the FBG is fixed on the measured object to measure the strain directly or fixed on an elastic structure body to measure other physical quantities, these types of FBGs can be collectively called as strain sensing FBGs. The packaging method of the FBG has important influence on the characteristics that directly affect the measurement accuracy, such as strain transfer, temperature characteristics, and spectral shape. Therefore, the packaging methods and corresponding temperature compensation methods of the currently reported strain sensing FBGs focus especially on the packaging of the fully pasted FBG, packaging of the pre-stretched FBG with double-end fixed, and metallic packaging. Furthermore, the advantages and drawbacks of different packaging methods have been analyzed, which can provide a reference for future researches.

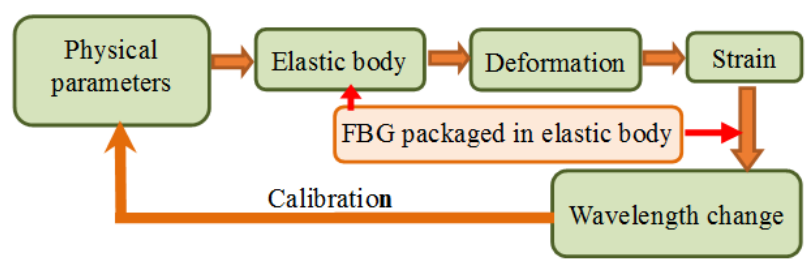

Fig. 2 Schematic diagram of the strain sensing FBG

\section{Overview of packaging methods}

Currently, the most commonly used packaging material for fixing fiber grating is epoxy adhesive (such as optical adhesive 353ND, made by Epoxy Technology, Inc.), that is, the fiber grating is fixed to the measured substrate by using adhesive. Here, the research overview of the non-metallic epoxy adhesive packaging and the emerging metallic packaging will be presented. 


\subsection{Packaging of fully pasted FBG}

As shown in Fig. 3, the FBG is embedded in the substrate or fully fixed on the surface of the substrate by using adhesive in this packaging method, which is common in general test work and sensor design. The advantage of this method is that the grating doesn't slack because the strain state of the grating between the load strain and the cold and thermal strains of the substrate is consistent. However, the drawback of this method is that the FBG easily suffers from chirping failures due to the non-uniform strain distribution and uneven adhesive thickness of the pasted grating, thereby causing an inaccuracy value of wavelength. In addition, the strain transfer ratio from the FBG to the substrate is affected by some random factors such as the length and thickness of the adhesive area, consequently, which will affect the measurement accuracy of the FBG $[8,9]$.

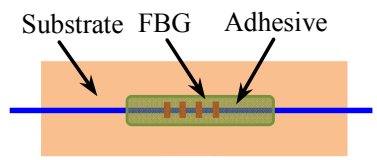

(a)

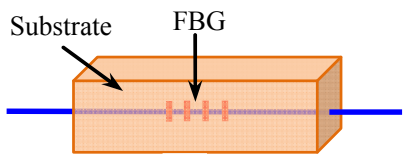

(b)
Fig. 3 Full package structure diagram of fiber optic grating: (a) fixed on the substrate surface and (b) embedded in the substrate.

It is well known that a method of temperature compensation for FBG sensing is needed to measure other physical parameters except temperature. The commonly used temperature compensation methods are the reference grating method and the dual-grating difference output method. The reference grating method is that it places two gratings with the same performance into the same temperature field. The purpose is to ensure that any temperature changes have the same effect on the two gratings. One of the gratings is used as a reference grating and protected from stress, which is used only to detect ambient temperature changes. Temperature compensation can be achieved by subtracting the wavelength shift caused by the temperature change from the total wavelength shift measured by the measuring grating [10-12]. This method of temperature compensation is simple and operable, but it has a flaw that when the external temperature changes fast, the two gratings could suffer from a big difference in their response time.

The dual-grating difference output method is that two FBGs with the same performance are pasted on the positive and negative strains of the substrate, respectively [13-15]. When the substrate is elastically deformed, one of the FBGs is stretched while the other one is compressed, and the influences of the ambient temperature on the two FBGs are considered to be identical. The difference of these two FBGs wavelength shifts can eliminate the cross-sensitivity of temperature, and the measurement sensitivity of the FBG can be improved.

The strain transfer ratio from the FBG to the substrate is affected by some random factors such as the length and thickness of the adhesive area, which will affect the measurement accuracy of the FBG. Moreover, this can lead to a difference of the grating wavelength by the cold and thermal strains of the substrate under the influence of environmental temperature. The defect of the temperature compensation under this packaging method is that the difference becomes more indefinite with the aging of the adhesive.

As shown in Fig. 4, for a high-temperature and high-pressure FBG sensor designed by Zhou et al. [10], a thin-walled $\mathrm{Al}_{2} \mathrm{O}_{3}$ tube is used as the substrate. FBG1 is axially stuck on the inner wall surface of the $\mathrm{Al}_{2} \mathrm{O}_{3}$ thin-wall tube to detect pressure. FBG2 is loosely fixed in the thin-wall tube as a reference grating to achieve temperature compensation. As shown in Fig. 5, for a long-range displacement FBG sensor designed by Li et al. [11], FBG1 is attached applying a glue to the one end of the spring as a displacement FBG, which keeps fixed by the sensor package. FBG2 is allowed to hang 
freely inside the metal case to ensure that this sensor does not take any mechanical strain and measures only the temperature change.

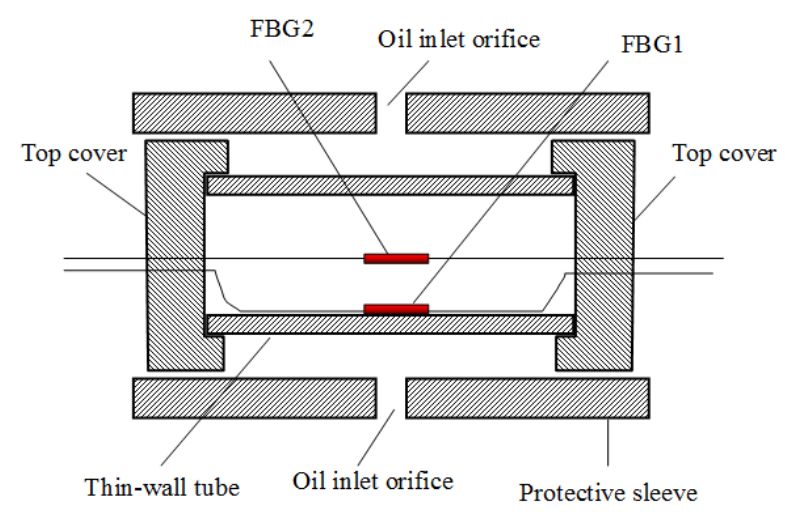

Fig. 4 Structural schematic diagram of the pressure sensor.

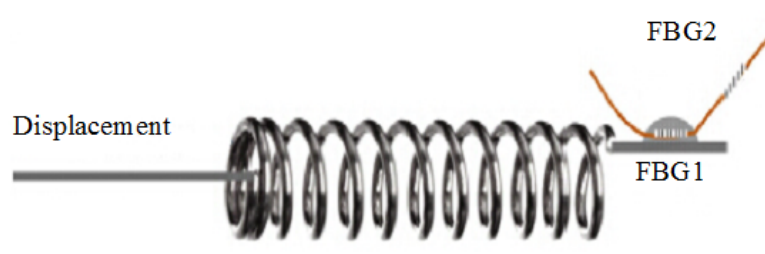

Fig. 5 Schematic of the sensing head of the long-range displacement sensor.

As shown in Fig. 6, for a sliding type FBG displacement sensor designed by Guo et al. [12], FBG1 is fixed on the lower surface of an equal intensity cantilever, which is used as a displacement FBG. For temperature compensation, FBG2 is loosely fixed on the platform surface of the sensor base as a reference grating. In [12], the temperature response time problem of two gratings involved in the temperature compensation process is investigated. As shown in Fig. 7, the response time of FBG2 lags behind that of FBG1. That is because FBG2 is a bare grating and it only senses the temperature inside the sensor. However, FBG1 is attached to the elastic beam and is sensitive to the thermal strain on the beam during the temperature change. As a result, the response time to temperature of FBG1 is faster than that of FBG2. Therefore, the compensation method is applied to the measurement environment where the rate of temperature changes slightly.

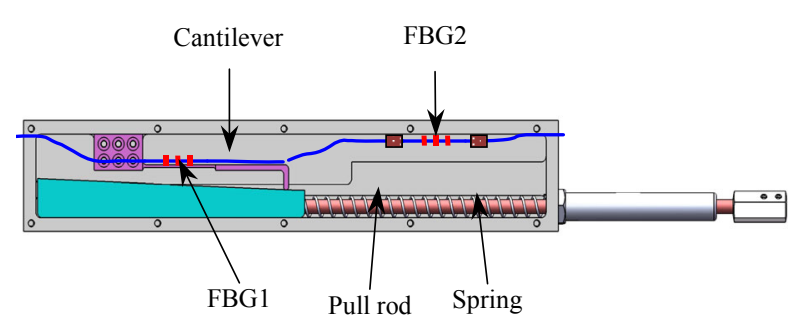

Fig. 6 Overall structure of an FBG displacement sensor.

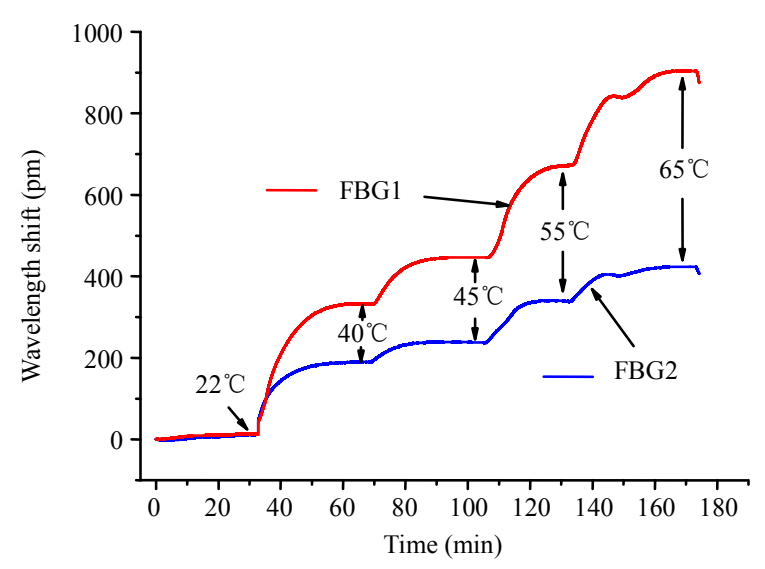

Fig. 7 Time-history curve of the temperature.

As shown in Fig. 8, for a diaphragm-type pressure FBG sensor designed by Huang et al. [13], FBG1 is fixed on the range between the diaphragm $R / \sqrt{3}$ and $R$, which is able to detect the radial negative strain of the diaphragm. While FBG2 is fixed on the central area of the diaphragm, which is used to explore the central positive strain of the diaphragm. Finally, the influence of temperature is eliminated by using the wavelength shift difference to achieve temperature compensation. As shown in Fig. 9, for a vacuum electrostatic voltage FBG sensor designed by Zhang et al. [14], two FBGs are symmetrically fixed on the same central axis of the equal strain beam. One of the FBGs detects the positive strain, while the other one detects the negative strain. Temperature compensation is achieved by the wavelength shift difference of two FBGs. As shown in Fig. 10, for a three-axis force fingertip FBG sensor designed by Guo et al. [15], FBG1 - FBG4 are adhered on the surface near the bottom of beams using a commercial adhesive, which are used to measure the axial forces on the $X$ and the $Y$ axes. The wavelength shift difference of 
these two-group FBGs are used to eliminate the temperature effects.

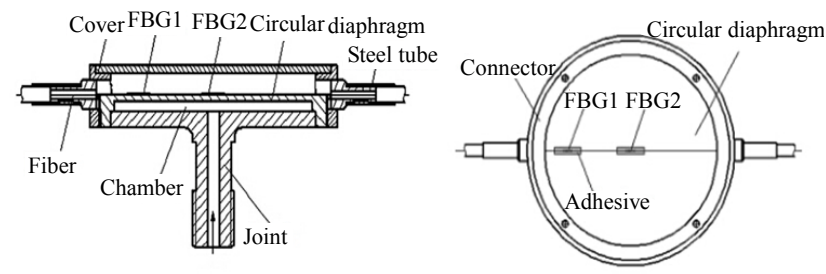

Fig. 8 Structure of the diaphragm-type FBG pressure sensor.
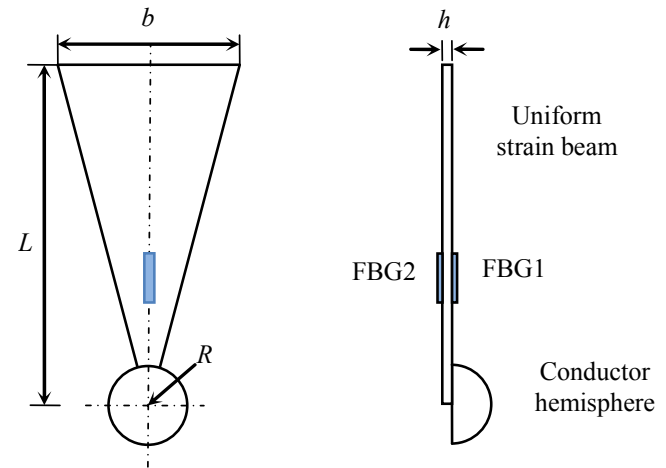

Fig. 9 Structure diagrams of uniforms train beam and twin-FBGs.
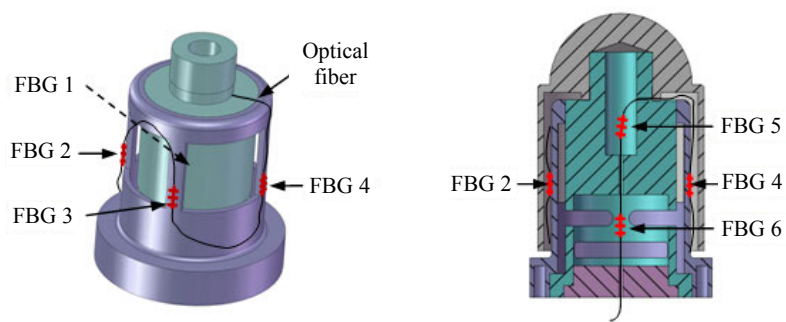

Fig. 10 Structure of the three-axis force fingertip sensor.

As shown in Fig. 11, for an embedded FBG sensor designed by Sun et al. [16], the FBG is embedded in a cylindrical specimen and deforms together with the specimen. As shown in Fig. 12, for a double FBGs vibration sensor designed by Wang et al. [17], two FBGs are embedded in elastic materials, which are used to detect vibration. When the FBG vibration sensor is under axial vibration, one of the cylinders is compressed while the other one is expanded, leading to a wavelength shift of the FBGs. Finally, the temperature compensation is achieved by the wavelength shift difference.

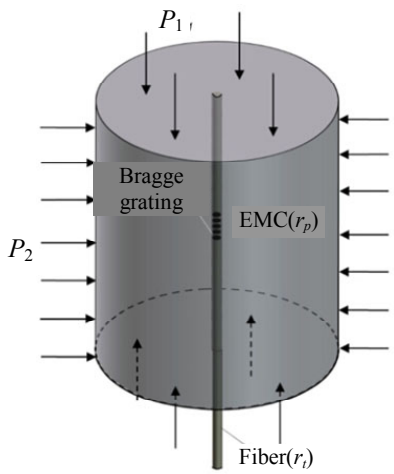

Fig. 11 Embedded packaging diagram.

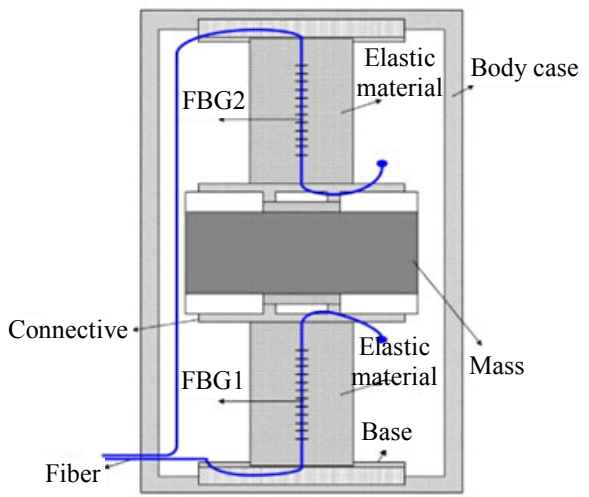

Fig. 12 Schematic of the FBG vibration sensor head.

\subsection{Packaging of pre-stretched FBG with double-end fixed}

As shown in Fig. 13, the FBG is suspended with a pre-tension force, and its two ends are glued on the substrate. The advantages of this packaging method are as follows:

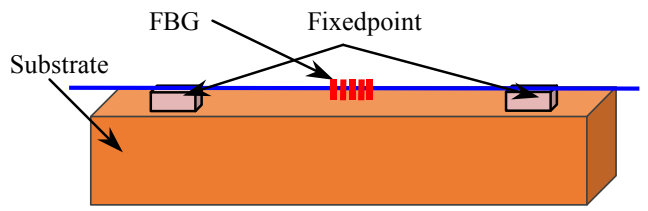

Fig. 13 Two-point packaging structure of the fiber optic grating.

(1) The deformation strain and thermal strain of the substrate are transferred to the FBG through the fixed end, which avoids the irregular errors due to uneven adhesion and expansion of the adhesive.

(2) The strain exerted on the grating is uniform, which avoids the chirp phenomenon.

However, the disadvantages of this packaging 
method are as follows:

(1) The preliminary drawing value of the pre-stretched FBG wavelength is constant. When the negative strain of the substrate exceeds the preliminary drawing value of the FBG, consequently, the grating is free. That is, the FBG cannot continue to sense the negative strain of the substrate, resulting in sensor failure.

(2) In the absence of negative deformation strain in the substrate, if the thermal expansion coefficient of the substrate material is greater than that of the grating, it will cause the preliminary drawing value of the FBG wavelength to reduce gradually until disappear. As a result, the grating will be in a slack state, which can result in an inaccurate measurement result.

(3) In addition, this kind of packaging method lacks sealing schedules, so the FBG and adhesive are exposed in air, which is liable to moisture and ultraviolet attack.

Moreover, because the wavelength shift of the FBG is influenced by both the axial strain and temperature, the temperature compensation is also needed for this packaging method of the pre-stretched FBG with double-end fixed. Under the influence of the external ambient temperature, the grating will be affected by the cold and thermal strains of the substrate as well as the thermal expansion and thermo-optic effects of the FBG. The most commonly used methods for temperature compensation are: (a) the reference grating method and (b) the double grating difference output method.

Packaging of the pre-stretched FBG with double-end fixed can be used for the design of different types of FBG sensors (e.g., pressure sensors, displacement sensors, and vibration sensors). As shown in Fig. 14, for a pressure FBG sensor designed by Zhang et al. [18], two FBGs are affixed at the middle area of the outer surface of the sensing shell in perpendicular directions, the axial direction for the temperature compensation FBG and the tangential direction for the sensing FBG. When the hydraulic pressure acts on the inner surface of the sensing cylinder, the tangential strain induces the red wavelength shift in the sensing FBG. A pull-type displacement FBG sensor designed by Zhang et al. [19] is shown in Fig. 15. If the measured displacement $S$ is less than or equal to $100 \mathrm{~mm}$, the pull wire acts on Spring 1 by the adjusting device. This displacement is then transferred to the FBGs, where FBG1 acts as the measuring grating and FBG2 acts as the reference grating. If the measured displacement $S$ is more than $100 \mathrm{~mm}$, the adjustment device releases Spring 1 to restore its free state. Meanwhile, the pull wire acts on Spring 2, where FBG2 acts as the measuring grating and FBG1 acts as the reference grating.

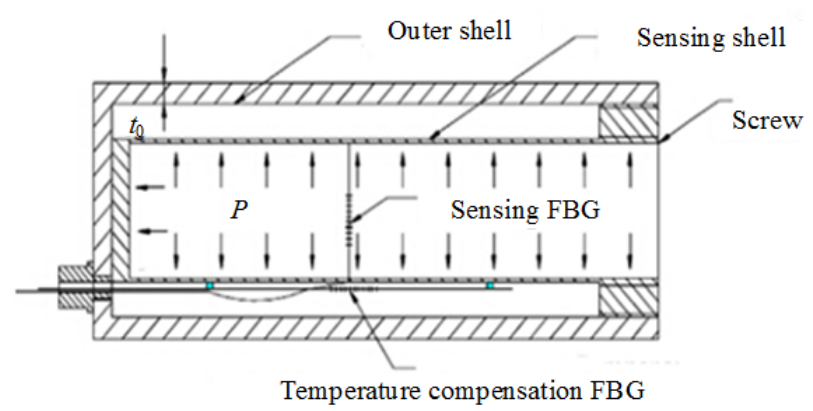

Fig. 14 FBG pressure sensor scheme.

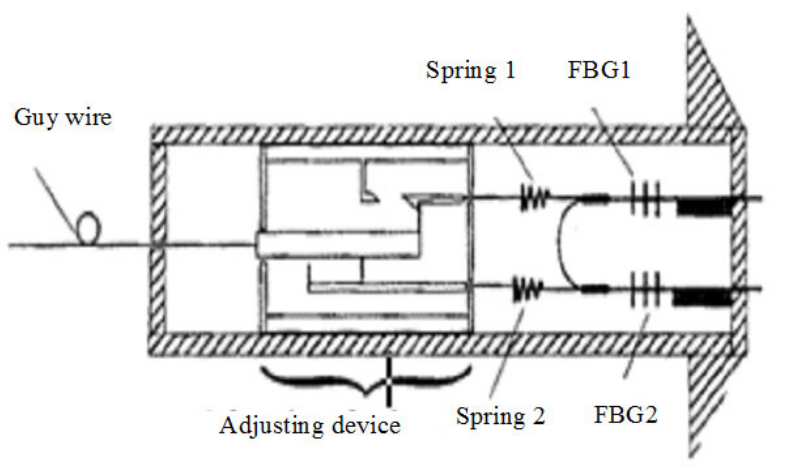

Fig. 15 Structure of the pull-type FBG displacement sensor.

A pressure FBG sensor designed by Vengal et al. [20] is shown in Fig. 16. FBG1 is firmly glued between two end positions of the metal bellows structure to measure the pressure. FBG2 is loosely fixed between two end positions of the metal bellows structure and used as a reference grating for temperature compensation. As shown in Fig. 17, for 
a non-contact FBG vibration sensor designed by $\mathrm{Li}$ et al. [21, 22], FBG1 is fixed between two end positions of the sensor structure, which is used as an elastic element to measure the acceleration. And FBG2 is hanged freely in the air as a reference grating for temperature compensation. In [15], the fiber on either side of FBG6 is fixed in the micro central holes of the inner measuring body and the bottom cover. FBG5 is hanged freely in the cavity of the inner measuring body to serve as the temperature compensation FBG for FBG6. As shown in Fig. 18, for a diaphragm-type FBG vibrating sensor designed by $\mathrm{Li}$ et al. [23], two pre-stretched FBGs are symmetrically arranged along the sides of the diaphragm in parallel. The two middle points of the optical fibers are connected with the top and bottom surfaces of the mass block using rigid rods to sense vibrations. The influence of temperature is eliminated using the difference output method. As shown in Fig. 19, for a reusable surface-mounted optical fiber Bragg grating strain sensor designed by Guo et al. [24], an FBG is adhered on the groove in the elastic body after an axial pre-tension, which allows the ability to measure negative strain. Because of the limited pre-tension, the limit on the measured negative strain of the sensor is $-600 \mu \varepsilon$.

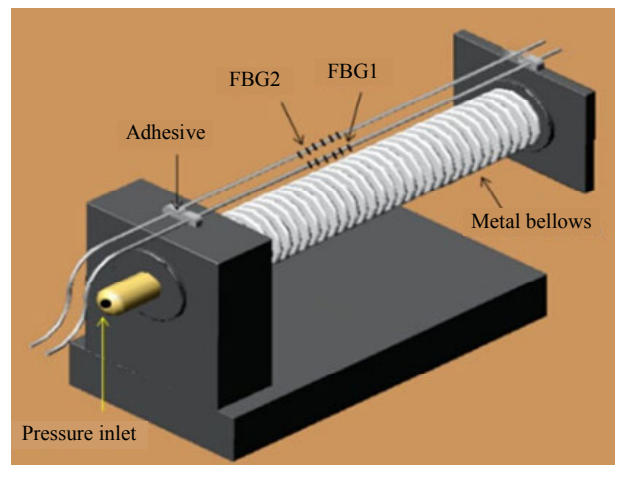

Fig. 16 Pressure sensor structure of the FBG.

\subsection{Metallic packaging}

Currently, the most commonly used packaging method of fiber grating sensor is adhesive packaging. However, the defects of adhesive packaging technique are as follows:

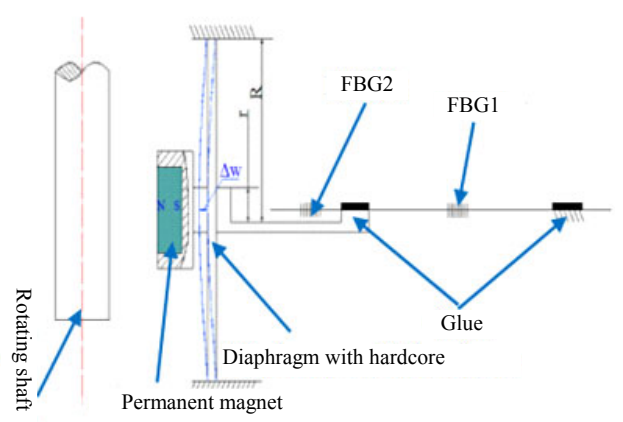

Fig. 17 Vibration sensor structure of FBG.

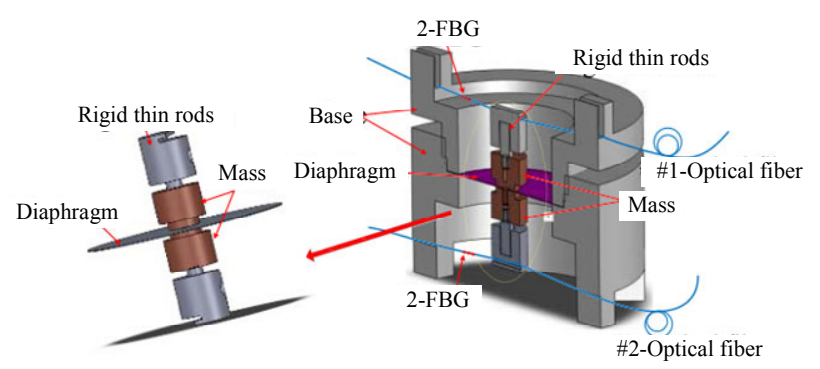

Fig. 18 Structure of the designed vibration sensor.

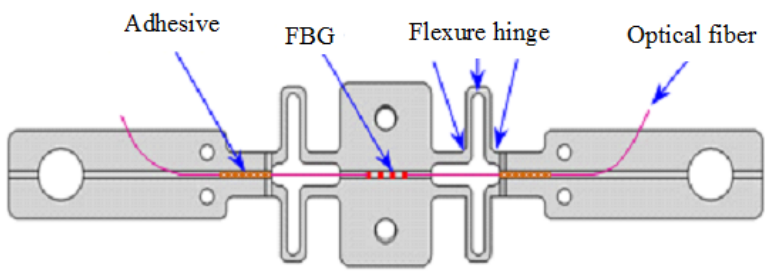

Fig. 19 Schematic of the elastic body and FBG arrangement.

(1) Adhesive-packaged FBG sensors cannot be used in harsh environments for a long time due to adhesive aging and creep phenomenon.

(2) When the FBG is used to measure temperature and strain in the sensing field, the coating layer of the fiber and adhesive can affect the linearity and repeatability of the measurement.

(3) The adhesive is generally greatly affected by the external environment.

When the temperature exceeds $120{ }^{\circ} \mathrm{C}$, the adhesive is easily to fall off which cannot be used for a slightly higher temperature measurement. Therefore, the metallic-packaged FBG sensors have been widely appreciated and studied due to the drawbacks of the adhesive-packaged sensors [25-29]. The excellent characteristic of 
metal-packaged sensor has benefited from the properties established by some metals and metallic compounds that are stable, durable, corrosion resistant, and resistant to high or low temperature [30]. However, It is difficult to directly package the fiber grating by using metallic materials due to the characteristics of metallic materials, such as high hardness, high melting point, and low associativity. Generally, magnetron sputtering, electroplating technology, and chemical plating technology are conjunctively adopted to metalize fiber. Then, the tin soldering or laser welding technology is adopted to fix the metal-coated fiber on the measurement substrate to obtain a fully metalized package without adhesives [31-34].

As shown in Fig. 20, for a pressure FBG sensor with a double-layer metallic cylindrical structure designed by Shen [35], the chemical plating and electroplating technologies are successively used to achieve metallic packaging of the FBG. The pressure measuring FBG1 is welded to the outer wall of the mid-section of the thin-walled inner metal tube (along the circumferential direction). FBG2 is welded to the top of the outer wall of the metallic thin-walled inner tube to eliminate the cross-sensitivity of temperature. As shown in Fig.21,

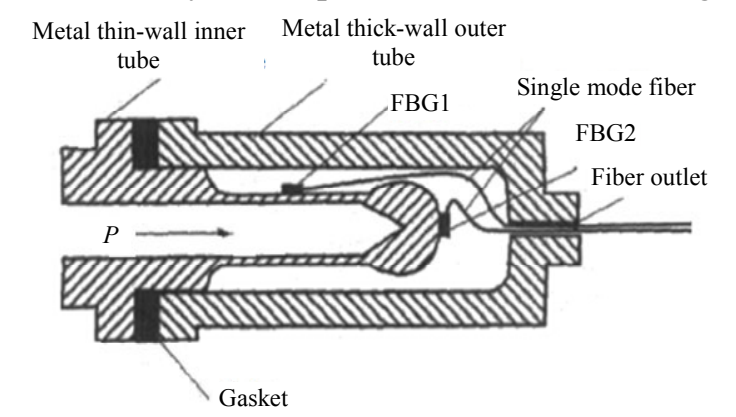

Fig. 20 Thin-walled strain tube FBG pressure sensor.

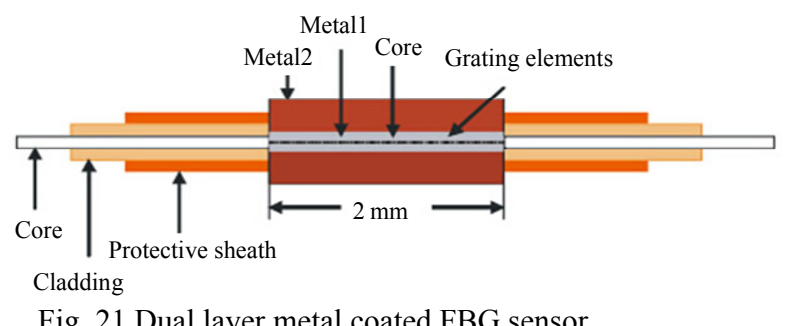

Fig. 21 Dual layer metal coated FBG sensor. for a metal-coated fiber Bragg grating sensor for sensing cryogenic temperature designed by Rajini-Kumar et al. [36], a double layered metal coating FBG is obtained by combining electro-deposition and vapor deposition. The thickness of the aluminum coating as the primary layer is $125 \mu \mathrm{m}$, and the thickness of the indium coating as the secondary layer is $625 \mu \mathrm{m}$.

As shown in Fig. 22, for an acceleration FBG sensor designed by Guo et al. [37, 38], the magnetron sputtering and electroplating technologies are successively used to conduct metallization encapsulation of fiber Bragg gratings. Then, the copper coated FBG is welded to the sensor component by using the laser welding technology. The sensor directly uses the metalized FBG as the elastic element to improve the elasticity coefficient and effectively avoid the stretching of the bare grating. As shown in Fig. 23, for a vibration FBG sensor designed by Nan et al. [39], the silver magnetron sputtering and nickel electroplating are used to achieve metallic packaging of the FBG. The nickel-plated FBG is welded to the sensor structure by using the laser welding technology. A metal-packaged regenerated fiber Bragg grating (RFBG) strain sensor designed by $\mathrm{Tu}[40,41]$ is shown in Fig. 24, and the optical fiber containing the RFBG is sputter-coated with a thin film of titanium (Ti) as an adhesive layer followed by a thin film of silver (Ag) as a conductive layer. The Ti-Ag-coated RFBG is then electroplated with a layer of nickel (Ni) as a protective layer. The process of nickel electro-deposition is also employed to embed the optical fiber into a modified 9Cr-1Mo (P91) steel substrate after coating the optical fiber with titanium, silver, and nickel multilayer coatings to realize metallic packaging of the RFBG.

Theoretically, the metallic packaging can avoid the aging of the adhesive and other related issues. However, since metallic packaging is a developing 
technology with the state of the technology being not completely mature. The technology needs a long time to be researched and developed. Moreover, the problems (e.g., rust, oxidation, and shedding) of the metallic packaged FBG have not been studied, which still are the major issues to be addressed in the future.
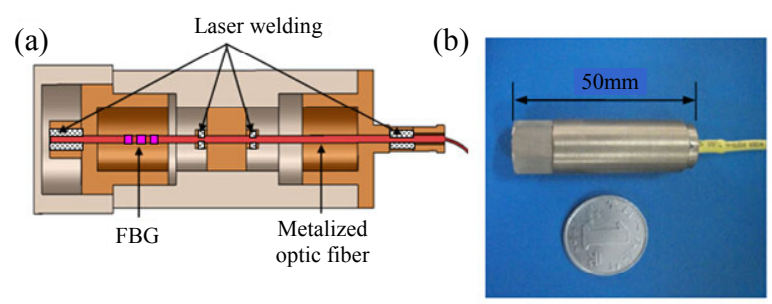

Fig. 22 FBG acceleration sensor: (a) metallic packaging structure and (b) actual image of the FBG accelerometer.
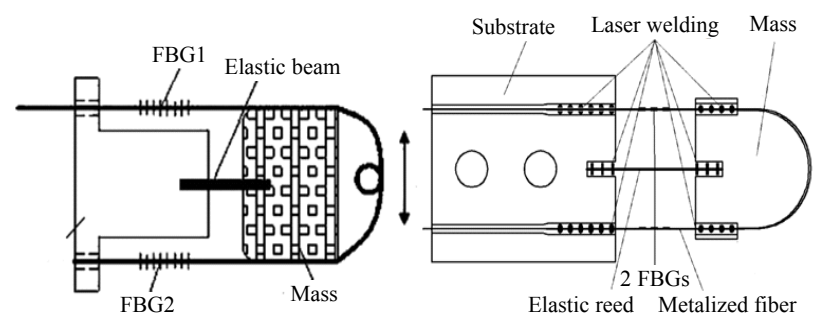

Fig. 23 Structure of the FBG vibration sensor.

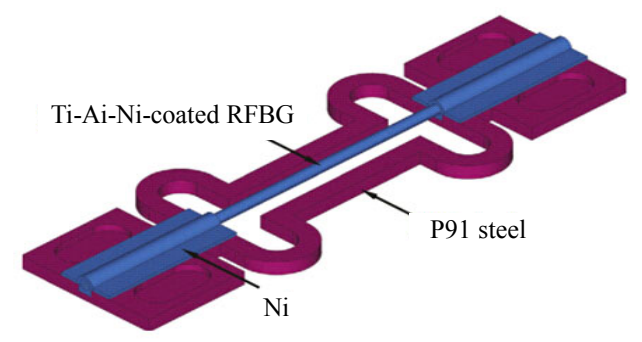

Fig. 24 A metal-packaged RFBG strain sensor.

\section{Results}

This paper mainly presents the packaging methods of the FBG in the sensor design and sensing fields. These methods have been introduced from three aspects: (a) packaging method of the fully pasted FBG, (b) packaging method of the pre-stretched FBG with double-end fixed, and (c) metallic packaging method. Furthermore, the main characteristics (e.g., advantages, drawbacks, application object, and temperature compensation) of these packaging methods are summarized in Table 1.

Table 1 Characteristics of the packaging methods.

\begin{tabular}{|c|c|c|c|c|}
\hline $\begin{array}{l}\text { Packaging } \\
\text { method }\end{array}$ & Advantages & Drawbacks & $\begin{array}{c}\text { Application } \\
\text { object }\end{array}$ & $\begin{array}{c}\text { Temperature } \\
\text { compensation }\end{array}$ \\
\hline $\begin{array}{l}\text { Full pasted } \\
\text { FBG }\end{array}$ & $\begin{array}{l}\text { Good sealing, } \\
\text { measuring } \\
\text { positive and } \\
\text { negative } \\
\text { strain without } \\
\text { the constrain } \\
\text { condition, } \\
\text { easy } \\
\text { operation }\end{array}$ & $\begin{array}{l}\text { Easy to chirp, } \\
\text { not affected } \\
\text { by adhesives }\end{array}$ & $\begin{array}{l}\text { Displacement } \\
\text { sensor, } \\
\text { pressure } \\
\text { sensor, } \\
\text { vibration } \\
\text { sensor, } \\
\text { strain sensor, } \\
\text { and so on }\end{array}$ & $\begin{array}{l}\text { Reference } \\
\text { grating } \\
\text { method and } \\
\text { dual-grating } \\
\text { difference } \\
\text { output } \\
\text { method }\end{array}$ \\
\hline $\begin{array}{l}\text { Pre-stretched } \\
\text { FBG with } \\
\text { double-end } \\
\text { fixed }\end{array}$ & $\begin{array}{c}\text { Avoid the } \\
\text { chirp } \\
\text { phenomenon, } \\
\text { easy } \\
\text { operation }\end{array}$ & $\begin{array}{l}\text { Lack sealing, } \\
\text { measuring } \\
\text { negative } \\
\text { strain is } \\
\text { limited due } \\
\text { to the } \\
\text { preliminary } \\
\text { drawing } \\
\text { value }\end{array}$ & $\begin{array}{l}\text { Displacement } \\
\text { sensor, } \\
\text { pressure } \\
\text { sensor, } \\
\text { vibration } \\
\text { sensor, strain } \\
\text { sensor, and so } \\
\text { on }\end{array}$ & $\begin{array}{l}\text { Reference } \\
\text { grating } \\
\text { method and } \\
\text { dual-grating } \\
\text { difference } \\
\text { output } \\
\text { method }\end{array}$ \\
\hline $\begin{array}{c}\text { Metallic } \\
\text { packaging }\end{array}$ & $\begin{array}{l}\text { Good sealing, } \\
\text { suitable for } \\
\text { harsh } \\
\text { environments }\end{array}$ & $\begin{array}{l}\text { Complex } \\
\text { manipulation, } \\
\text { easy to be } \\
\text { oxidized }\end{array}$ & $\begin{array}{l}\text { Mainly used } \\
\text { for } \\
\text { temperature } \\
\text { sensor, less } \\
\text { used for } \\
\text { strain sensor } \\
\text { and vibration } \\
\text { sensor }\end{array}$ & $\begin{array}{l}\text { Reference } \\
\text { grating } \\
\text { method and } \\
\text { dual-grating } \\
\text { difference } \\
\text { output } \\
\text { method }\end{array}$ \\
\hline
\end{tabular}

\section{Discussion}

(1) The packaging method of the fully pasted FBG can guarantee the FBG sealed well. However, the sticking technologies of adhesive, such as the uniformity, thickness, length, width, Young modulus, and other factors have an important effect on the measurement accuracy. Moreover, in order to avoid the chirp phenomenon, the packaging method requires that the strain distribution is uniform on the affixed area of the FBG.

(2) The packaging method of the pre-stretched FBG with double-end fixed can overcome the chirp problem accompanied with the FBG-pasting process. However, in order to guarantee the negative strain measurement, it is necessary to ensure the preliminary pre-stressing force on the FBG. In addition, this kind of packaging method lacks sealing schedules, so the FBG and adhesive are exposed in air, which is liable to moisture and ultraviolet attack.

(3) The excellent characteristic of metal-packaged FBG has benefited from the 
properties established by some metals and metallic compounds that are stable, durable, corrosion resistant, resistant to high or low temperature and no chirp phenomenon. However, since metallic packaging is a developing technology with the state of the technology being not completely mature. The durability of the metal-packaged FBG should be investigated because the metal will be oxidized in long-term use.

(4) At present, the main temperature compensation methods include the reference grating method and dual-grating difference output method. However, current research has not reported the consensus problem of response time to the temperature of the FBG. If the compensation method is applied to the measurement environment where the rate of temperature change is significant which will affect the measurement accuracy.

(5) The sticking craftsmanship of the adhesive is extremely important for the consistency and repeatability for FBG sensors, and a large amount of experiments and analysis are needed to validate and optimize this craftsmanship. Therefore, the following research fields are needed to strengthen in future: (a) creep degradation characteristics of double-end fixed packaging method; (b) temperature compensation characteristics of different packaging methods under different temperature changing rates; (c) the actual compensation effects of different packaging methods. In comparison with the adhesive packaging methods, the metallic packaging is a good choice for structural health monitoring in harsh environments such as high temperature, low temperature, and highly corrosive environment. However, there is a lack of further studies in sensor design and sensing fields, such as durability of metallic packaging, simple and convenient metallic packaging method, and lower manufacturing cost. Both the frontier theoretical research and basic packaging technology should be given more attention by the scientific and technological community. In this way, the FBG sensing technology will be improved and developed, and will have more considerably potential applications.

\section{Conclusions}

This paper summarizes the characteristics, advantages, and drawbacks of three packaging methods for the strain sensing FBG, which can provide important help for future research fields such as sensor design, signal processing, and structural health monitoring. Among them, the sticking technology of the adhesive is extremely important for the consistency and repeatability for the adhesive-packaged sensors, and a large amount of experiments and analysis are needed to validate this knowledge. However, there a lack of comparative studies on the strain measurement of the FBG under different encapsulation methods and the actual compensation effects of different packaging methods, so these studies should be given more attention by future researchers. Furthermore, with a rapid development in the field of the optical fiber manufacturing technology and materials science, the packaging method and novel packaging materials of special fibers (micro- and nano-fibers, photonic crystal fibers, etc.) are also an indispensable subject in the future research.

\section{Acknowledgment}

This paper was partially supported by the Natural Science Foundation of China under Grant No. 51605348, the Natural Science Foundation of Hubei province under Grants No. 2016CFB116, and the Project of China Postdoctoral Science Foundation under Grant No. 2015M572208.

Open Access This article is distributed under the terms of the Creative Commons Attribution 4.0 International License (http://creativecommons.org/licenses/by/4.0/), which permits unrestricted use, distribution, and reproduction in any medium, provided you give appropriate credit to the original author(s) and the source, provide a link to the Creative Commons license, and indicate if changes were made. 


\section{References}

[1] K. O. Hill, Y. Fujii, D. C. Johnson, and B. S. Kawasaki, "Photosensitivity in optical fiber waveguides: application to reflection filter fabrication," Applied Physics Letters, 1978, 32(10): 647-649.

[2] B. S. Kawasaki, K. O. Hill, D. C. Johnson, and Y. Fujii, "Narrow-band Bragg reflectors in optical fibers," Optics Letters, 1978, 3(2): 66-68.

[3] W. W. Morey, G. Meltz, and W. H. Glenn, "Fiber optic Bragg grating sensors," SPIE, 1990, 1169(96): 98-107.

[4] Y. X. Guo, D. S. Zhang, J. J. Fu, S. B. Liu, S. Z. Zhang, and F. D. Zhu, "Development and operation of a fiber Bragg grating based online monitoring strategy for slope deformation," Sensor Review, 2015, 35 (4): 348-356.

[5] T. L. Li, Y. G. Tan, Y. Liu, A. Qu, M. Y. Liu, and Z. D. Zhou, "A fiber Bragg grating sensing based triaxial vibration sensor," Sensors, 2015, 15(9): 24214-24229.

[6] J. A. Chen, D. Huang, H. T. Zhao, Q. B. Wang, Y. Qiu, and D. P. Duan, "Fiber Bragg grating-based plane strain monitoring of aerostat envelope structures," Applied Optics, 2013, 52(19): 4631-4639.

[7] L. Xiong, G. Z. Jiang, Y. X. Guo, and H. H. Liu, “A three-dimensional fiber Bragg grating force sensor for robot," IEEE Sensors Journal, 2018, 18(9): 3632-3639.

[8] K. Wan, "Quantitative sensitivity analysis of surface attached optical fiber strain sensor," IEEE Sensors Journal, 2014, 14(6): 1805-1812.

[9] R. J. Wu, B. L. Zheng, Z. G. Liu, P. F. He, and Y. G. Tan, "Analysis on strain transfer of a pasted FBG strain sensor," Optik - International Journal for Light and Electron Optics, 2014, 125(17): 4924-4928.

[10] H. Zhou, X. G. Qiao, H. L. Wang, D. Q. Feng, and W. Wang, "Study of a high-temperature and high-pressure FBG sensor with $\mathrm{Al}_{2} \mathrm{O}_{3}$ thin-wall tube substrate," Optoelectronics Letters, 2008, 4(4): 260-263.

[11] J. Li, H. Neumann, and R. Ramalingam, "Design, fabrication, and testing of fiber Bragg grating sensors for cryogenic long-range displacement measurement," Cryogenics, 2015, 68: 36-43.

[12] Y. X. Guo, L. Xiong, J. Y. Kong, Z. Y. Zhang, and L. Qin, "Sliding type fiber Bragg grating displacement sensor," Optics and Precision Engineering, 2017, 25(1): 50-58.

[13] J. Huang, Z. D. Zhou, X. Y. Wen, and D. S. Zhang, "A diaphragm-type fiber Bragg grating pressure sensor with temperature compensation," Measurement Journal of the International Measurement Confederation, 2013, 46(3): 1041-1046.

[14] Y. D. Zhang, K. Y. Zhang, and H. Zhao, "Vacuum electrostatic voltage sensors based on uniform strain beam and twin-FBGs with temperature compensation," Journal of Optoelectronics.Laser, 2015, 26(8): 1448-1453.

[15] Y. X. Guo, J. Y. Kong, H. H. Liu, H. G. Xiong, G. F. $\mathrm{Li}$, and L. Qin, "A three-axis force fingertip sensor based on fiber Bragg grating," Sensors and Actuators A: Physical, 2016, 249: 141-148.

[16] Y. Sun, H. S. Lee, and B. Han, "Measurement of elastic properties of epoxy molding compound by single cylindrical configuration with embedded fiber Bragg grating sensor," Experimental Mechanics, 2017, 57: 313-324.

[17] J. F. Wang, Y. Yu, Y. Chen, H. Luo, and Z. Meng, "Research of a double fiber Bragg gratings vibration sensor with temperature and cross axis insensitive," Optik - International Journal for Light and Electron Optics, 2015, 126(7-8): 749-753.

[18] W. T. Zhang, F. Li, and Y. L. Liu, "FBG pressure sensor based on the double shell cylinder with temperature compensation," Measurement, 2009, 42(3): 408-411.

[19] Y. J. Zhang, B. K. Huang, B. Wei, B. B. Jia, and W. H. Bi, "Experiment research in slope monitoring based on fiber Bragg grating sensing technology," Optical Technology, 2011, 37(2): 208-212.

[20] V. R. Pachava, S. Kamineai, S. S. Madhuvarasu, K. Putha, and V. R. Mamidi, "FBG based high sensitive pressure sensor and its low-cost interrogation system with enhanced resolution," Photonic Sensors, 2015, 5(4): 321-329.

[21] T. L. Li, Y. G. Tan, Z. D. Zhou, L. Cai, S. Liu, Z. T. $\mathrm{He}$, et al., "Study on the non-contact FBG vibration sensor and its application," Photonic Sensors, 2015, 5(2): 128-136.

[22] T. L. Li, Y. G. Tan, Z. D. Zhou, and K. Zheng, "A non-contact FBG vibration sensor with double differential temperature compensation," Optical Review, 2016, 21(3): 26-32.

[23] T. L. Li, C. Y. Shi, Y. G. Tan, R. Y. Li, Z. D. Zhou, and H. L. Ren, "A diaphragm type fiber Bragg grating vibration sensor based on transverse property of optical fiber with temperature compensation," IEEE Sensors Journal, 2016, 17(4): 1021-1029.

[24] Y. X. Guo, J. Y. Kong, H. H. Liu, D. T. Hu, and L. Qin, "Design and investigation of a reusable surface-mounted optical fiber Bragg grating strain sensor," IEEE Sensors Journal, 2016, 16(23): 8456-8462.

[25] K. Tai, A. Hasegawa, and A. Tomita, "Embedding optical fibers in metal alloys," Instrumentation \& Measurement Magazine IEEE, 2003, 6(2): 31-36.

[26] D. Fan, "Experimental study of sense characteristic based on metalized package fiber Bragg grating," Chinese Journal of Sensors and Actuators, 2006, 1234-1237.

[27] R. Teng, S. H. Song, R. S. Shen, Y. S. Zhang, and 
G. T. Du, "Study on electroless plating of nickel and electroplating of stannum on quartz optical fiber," Optical Technique, 2008, 34: 87-88.

[28] B. Shui, "Study on sensing technology of metal coating fiber Bragg grating," Ph.D. dissertation, Wuhan University of Technology, Wuhan, China, 2012.

[29] Y. Feng, H. Zhang, Y. L. Li, and C. F. Rao, "Temperature sensing of metal-coated fiber Bragg grating," IEEE/ASME Transactions on Mechatronics, 2011, 15(4): 511-519.

[30] Y. M. Zhang, L. Q. Zhu, F. Luo, M. L. Dong, R. T. Yang, W. He, et al., "Comparison of metal-packaged and adhesive-packaged fiber Bragg grating sensors," IEEE Sensors Journal, 2016, 16(15): 2958-5963.

[31] Y. L. Li, H. Zhang, Y. Feng, and G. Peng, "Metal coming of fiber grating and the temperature sensing character after metallization," Optical Fiber Technology, 2009, 15(4): 391-397.

[32] Y. Feng, H. Zhang, Y. L. Li, and G. Peng, "Temperature sensitization model of fiber Bragg grating with metal coating," Acta Optica Sinica, 2009, 29(2): 336-341.

[33] S. W. Lu, J. J. Wang, H. J. Zhang, and Y. Gao, "Fabrication of fiber Bragg grating sensor coated with nickel plate on Sn-Al substrate," Journal of Optoelectronics Laser, 2012, 23(10): 1847-1850.

[34] Y. L. Lo and C. P. Kuo, "Packaging a fiber Bragg grating with metal coming for an athermal design," Journal of Lightwave Technology, 2003, 21(5): 1377-1383.

[35] R. Shen, "Research of metal-coated and sensing technology applications on FBG," Ph.D. dissertation, Dalian University of Technology, Dalian, China, 2008.

[36] R. Rajini-Kumar, M. Suesser, K. G. Narayankhedkar, G. Krige, and M. D. Atrey, "Performance evaluation of metal-coated fiber Bragg grating sensors for sensing cryogenic temperature," Cryogenics, 2008, 48(3): 142-147.

[37] Y. X. Guo, D. S. Zhang, Z. D. Zhou, L. Xiong, and X. W. Deng, "Welding-packaged accelerometer based on metal-coated FBG," Chinese Optics Letters, 2013, 11(7): 21-23.

[38] Y. X. Guo, D. S. Zhang, H. Meng, X. Y. Wen, and Z. D. Zhou, "Metal packaged fiber Bragg grating accelerometer," SPIE - The International Society for Optical Engineering, 2012, 8421: 84213V-1$84213 \mathrm{~V}-4$

[39] Q. Nan, H. U. Wu, and S. Li, "Metallization packaging method for FBG vibration sensor," Transactions of the China Welding Institution, 2016, 37(2): 17-20.

[40] Y. Tu and S. T. Tu, "Fabrication and characterization of a metal-packaged regenerated fiber Bragg grating strain sensor for structural integrity monitoring of high-temperature components," Smart Materials \& Structures, 2014, 23(3): 35001-35011.

[41] Y. Tu, Y. H. Qi, and T. S. Tu, "Fabrication and thermal characteristics of Ti-Ag-Ni coated regenerated grating sensors for high-temperature sensing," Smart Materials \& Structures, 2013, 22(7): 075026-1-075026-7. 